\title{
ANCYLOSTOMA DUODENALE EM ESTRANGEIROS RADICADOS EM BOTUCATU, SP, BRASIL*
}

\author{
Florence F.S. Kerr * e Fernando M.A. Corrêa***
}

\begin{abstract}
Utilizando-se a técnica de Harada \& Mori foi efetuada verificação das espécies de Ancylostomidae prevalentes entre imigrantes europeus, asiáticos e brasileiros residentes no municipio de Botucatu, Estado de São Paulo, Brasil.

Ancylostoma duodenale foi encontrado em $8,5 \%$ dos imigrantes asiáticos e Necator americanus em 3,5\% dos europeus e em $18 \%$ dos brasileiros examinados.
\end{abstract}

\section{INTRODUÇÃO}

Embora seja o Necator americanus a espécie de ancilostomídeo prevalente no homem, em nosso meio, Pessoa ${ }^{6}$ assinala ter Smille encontrado o Ancylostoma duodenale em estrangeiros aqui radicados.

Tendo em vista a facilidade de identificação das larvas desses ancilostomídeos possibilitada pela técnica descrita por Harada \& Mori ${ }^{4}$ e a existência no município de Botucatu, Estado de São Paulo, de dois grupamentos alienígenas, um de procedência européia e outro constituído por imigrantes asiáticos, julgamos ter resultados inter essantes examinando material fecal dos indivíduos integrantes desses dois grupamentos populacionais. Para efeito de comparação examinamos também material fecal de individuos da população brasileira, constituindo um terceiro grupo de residentes do mesmo município.

\section{MATERIAL E MÉTODOS}

\section{Grupamentos populacionais}

Foram examinadas amostras fecais de indi- víduos pertencentes a três grupamentos populacionais, a saber:

GRUPO 1 - Constituido por 57 pessoas, pertencentes a diversas faixas etárias, imigrantes procedentes da Bélgica e radicados, à época em que foram recolhidas as amostras por tempo não superior a sete anos no município de Botucatu (Fazenda Monte Alegre), onde se dedicavam à exploração agro-pecuária.

GRUPO 2 - Constituido por 47 pessoas, pertencentes a diversas faixas etárias, imigrantes procedentes do Japão e de Formosa e radicados, à época em que foram recolhidas as amostras, por período não maior que quatro anos no mesmo município (Colônia Santa Marina), onde se dedicavam a práticas horti-frugi-granjeiras.

GRUPO 3 - Constituido por 50 pessoas de nacionalidade brasileira, pertencentes a diversas faixas etárias, trabalhadores agrícolas ou servidores das Ferrovias Paulistas S.A. (FEPASA) e seus familiares, radicados no distrito de Rubião Júnior do mesmo município.

\section{MÉTODOS EMPREGADOS}

As amostras fecais provenientes de cada um

- Trabalho do Departamento de Parasitologia do IBBMA - Campus de Botucatu - UNESP, realizado, em parte, com o auxilio da FAPESP.

* Bolsista da FAPESP.

* * Professor Titular do Departamento de Parasitologia do IBBMA - Campus de Botucatu - UNESP. 
dos indivíduos examinados foram submetidas a exame, empregando-se em cada caso o método de Faust et al. ${ }^{3}$, o método de Hoffmann, Pons \& Janer 5 e o método de Baermann ${ }^{1}$. As amostras que se mostraram positivas para ovos de ancilostomídeos foram submetidas à cultura, obedecida a técnica descrita por Harada \& Mori $^{4}$.

\section{RESULTADOS}

Nossos resultados acham-se expressos nas Tabelas I, II e III.

\section{TABELA I}

Resultados de culturas de larvas e de exames de fezes de indivíduos de procedência belga.

\begin{tabular}{|c|c|c|c|c|}
\hline Individuos & FAUST et al. & HOFFMANN & BAERMANN & HARADA \& MORI \\
\hline 1 & Ancilostomídeos & - & - & N. americanus \\
\hline 1 & Ancilostomídeos & Ancilostomídeos & - & N. americanus \\
\hline 6 & G. lamblia & - & - & - \\
\hline 1 & $\begin{array}{l}\text { E. histolytica } \\
\text { E. coli }\end{array}$ & - & - & - \\
\hline 1 & I. bütschlii & - & - & - \\
\hline 1 & - & Taenia sp. & - & - \\
\hline 46 & - & - & - & - \\
\hline
\end{tabular}

\section{TABELA II}

Resultados de culturas de larvas e de exames de fezes de indivíduos de procedência asiática.

\begin{tabular}{c|l|c|c|c}
\hline $\begin{array}{c}\text { No de } \\
\text { Indivíduos }\end{array}$ & Métodos & HOFFMANT et al. & BAERMANN & HARADA \& MORI \\
\hline 2 & $\begin{array}{l}\text { Ancilostomideos } \\
\text { Ancilostomideos } \\
\text { G. lamblia }\end{array}$ & - & - & A. duodenale \\
& $\begin{array}{l}\text { Ancilostomideos } \\
\text { E. vermiculares } \\
\text { T. trichiura } \\
1\end{array}$ & 1 & - & A. duodenale \\
1 & $\begin{array}{l}\text { T. trichiura } \\
\text { H. nana }\end{array}$ & - & 1 & A. duodenale \\
1 & G. lamblia & - & - & - \\
1 & E. vermiculares & - & - & - \\
\hline
\end{tabular}




\section{TABELA III}

Resultados de culturas de larvas e de exames de fezes de indivíduos de nacionalidade brasileira.

\begin{tabular}{|c|c|c|c|c|}
\hline $\begin{array}{c}\text { Nọ de } \\
\text { Indivíduos }\end{array}$ & FAUST & HOFFMANN & BAERMANN & HARADA \& MORI \\
\hline 1 & $\begin{array}{l}\text { Ancilost. } \\
\text { A. lumbr. } \\
\text { T. trich. } \\
\text { E. histol. }\end{array}$ & - & - & N. americanus \\
\hline 1 & $\begin{array}{l}\text { Ancilost. } \\
\text { A. lumbr. } \\
\text { E. coli }\end{array}$ & - & A. lumbr. & N. americanus \\
\hline 2 & $\begin{array}{l}\text { Ancilost. } \\
\text { A. lumbr. } \\
\text { T. trich. }\end{array}$ & - & A. lumbr. & N. americanus \\
\hline 2 & $\begin{array}{l}\text { Ancilost. } \\
\text { T. trich. }\end{array}$ & - & - & N. americanus \\
\hline 1 & $\begin{array}{l}\text { Ancilost. } \\
\text { A. lumbr. } \\
\text { T. trich. } \\
\text { E. coli } \\
\text { G. lamblia }\end{array}$ & - & $\begin{array}{l}\text { A. lumbr. } \\
\text { T. trich. }\end{array}$ & N. americanus \\
\hline 1 & $\begin{array}{l}\text { Ancilost. } \\
\text { T. trich. } \\
\text { H. nana }\end{array}$ & - & - & N. americanus \\
\hline 1 & $\begin{array}{l}\text { Ancilost. } \\
\text { A. lumbr. } \\
\text { T. trich. }\end{array}$ & S. sterc. & A. lumbr. & $\begin{array}{l}\text { N. americanus } \\
\text { S. stercoralis }\end{array}$ \\
\hline 13 & $\begin{array}{l}\text { A. lumbr. } \\
\text { T. trich. }\end{array}$ & - & A. lumbr. & - \\
\hline 3 & A. lumbr. & - & A. lumbr. & - \\
\hline 2 & E. vermic. & - & - & - \\
\hline 4 & E. coli & - & - & - \\
\hline 1 & G. lamblia & - & - & - \\
\hline 1 & $\begin{array}{l}\text { A. lumbr. } \\
\text { G. lamblia }\end{array}$ & - & A. lumbr. & - \\
\hline 1 & $\begin{array}{l}\text { A. lumbr. } \\
\text { E. coli }\end{array}$ & S. sterc. & A. lumbr. & S. stercoralis \\
\hline 1 & $\begin{array}{l}\text { A. lumbr. } \\
\text { T. trich. }\end{array}$ & S. sterc. & A. lumbr. & S. stercoralis \\
\hline 1 & H. nana & - & - & - \\
\hline 1 & T. trich. & - & - & - \\
\hline 2 & Taenia sp. & - & - & - \\
\hline 11 & - & - & - & - \\
\hline
\end{tabular}


Pelo exame dessas tabelas verifica-se que:

1 - na Fazenda Monte Alegre foram examinados 57 moradores, todos procedentes da Bélgica, sendo que, afora outros parasitas intestinais, as fezes de apens duas pessoas $(3,5 \%)$ apresentaram ovos de ancilostomídeos. Feitas as culturas dessas fezes ambas mostraram-se positivas somente para larvas de Necator americanus:

2 - na Colônia Santa Marina foram examinados 47 moradores, todos procedentes da Ásia, tendo sido encontradas, afora outros parasitas intestinais, quatro pessoas $(8,5 \%)$ infectadas por ancilostomideos. As culturas das fezes dessas quatro pessoas, todas vindas de Formosa e no Brasil há apenas um ano, à época em que foram realizados os exames, mostraram-se positivas para larvas de Ancylostoma duodenale;

3 - no distrito de Rubião Júnior foram examinados 50 moradores, todos brasileiros natos, dos quais, não considerados outros parasitas intestinais, nove $(18,0 \%)$ mostraram-se também parasitados por ancilostomídeos. Feitas as culturas dessas amostras fecais mostraram-se todas elas positivas para larvas de Necator americanus.

\section{DISCUSSÃO}

Fatores climáticos parecem ser os principais condicionantes da distribuição natural das espécies de ancilostomideos que acometem o homem: o Necator americanus predominando nas regiões tropical e sub-tropical e o Ancylostoma duodenale nas regiões mais frias.

Em que pese tal fato, é evidente que movimentos migratórios, mormente com a rapidez possivel atualmente, permitem a translocação de parasitoses e é sempre interessante estar atento para aspectos que possam decorrer.

Tendo tido conhecimento da existência de dois grupamentos alienígenas no município de Botucatu, pareceu-nos interessante verificar a possivel ocorrência de parasitoses não autóctones $\mathrm{e}$, inclusive, se fosse o caso, proceder o seguimento dos indivíduos por elas acometidos.

Ao dar início às nossas investigações junto aos imigrantes belgas moradores na Fazenda Monte Alegre, verificamos que seu tempo de residência em nosso país era superior ao que nos havia sido informado, atingindo, em alguns casos, sete anos. Embora nossos objetivos iniciais possam ter sido comprometidos por esse fato pois, segundo Chandler ${ }^{2}$, na ausência de reinfestações, a contagem de ovos de anci- lostomídeos após cinco anos pode cair em até $92 \%$. Os trabalhos deste mesmo autor também indicam que, mesmo após nove anos, pequeno número de ovos pode ainda ser encontrado.

Em nossas investigações nenhum dos imigrantes belgas mostrou-se parasitado pelo Ancylostoma duodenale. Dois deles mostraram-se parasitados pelo $N$. americanus porém não foi possivel avaliar quando teria ocorrido a infestação. Cumpre ressaltar que as condições de moradia e os hábitos higiênicos e alimentares dos indivíduos pertencentes a esse grupo populacional mostravam-se de nivel bastante bom.

Na Colônia Santa Marina, à época em que foram coletadas as amostras fecais, os indivíduos residiam no máximo há quatro anos no Brasil e, embora as condições das moradias fossem bem mais singelas que aquelas ocupadas pelos belgas, mostravam nível higiênico e hábitos alimentares bons. Ali encontramos quatro indivíduos, originários de Formosa e residentes no Brasil há apenas um ano, que se mostraram portadores do $A$. duodenale. Embora não se possa avaliar quando contrairam a infestação, é quase certo afirmar que a trouxeram desde seu país de origem. Acreditamos ser pequena a possibilidade de que venham eles a reinfestar-se perpetuando a infestação porquanto, além das condições climáticas não parecerem adequadas ao desenvolvimento das larvas infestantes, a casa que habitam é dotada de fossa séptica.

Quanto ao grupo populacional constituido por brasileiros, consideramos que os resultados por nós encontrados são compatíveis com as condições sócio-econômicas e culturais apresentadas por seus integrantes. Como era de se esperar, no que respeita a ancilostomídeos, nos indivíduos positivos deste grupo o parasitismo era exercido apenas pelo Necator americanus.

\section{SUMMARY}

A survey of the species of Ancylostomidae causing infection among European inmigrants and Brazilian residents in Botucatu, São Paulo state, Brazil was performed using Harada \& Mori's technique.

Ancylostoma duodenale was found in $8.5 \%$ of the asiatic inmigrants and Necator americanus in $3.5 \%$ of the European and $18.0 \%$ of the Brazilians examined. 


\section{REFERENNCIAS BIBLIOGRÁFICAS}

1. BAERMANN, G. Eine einfache Méthode Zur Auffindung von Ankylostomun (Nematoden) Larven in Erdproden. Mededeel. und h. Geneesk. Lab. te Weltevreden, Feestbundel, Batvia, 41-47, 1917.

2. CHANDLER, A.C. A review of recen work on rate of acquisition and loss of hookworms. Am. J. Trop. Med., 15: 357-370, 1935.

3. FAUST, E.C.; D'ANTONI, J.S.; ODON, V.; MILLER, M.J.; PERES, C.;

SAWITT, J.S.; THOMEN, L.F.; TOBIE, J. \& WALKER, J.H. A critical study of clinical laboratory technics for the diagnosis of protozoan cysts and helminth eggs in feces. Am. J. Trop. Med., 18: 169, 1938.

4. HARADA, Y. et al. (1951) Igaku to Seibutsugaku, 20: 65 - In HSIEH, H.C. Méthode de culture sur papier filtre en tube à essai pour l'identification d'Ancylostoma duodenale, de Necator americanus et de Strangyloides stercoralis. Conferénce Africaine CCTA/OMS sur l'Ankylostomiase. O.M.S. Rapports Techniques no 225, Genève, 1963.

5. HOFFMANN, W.A.; PONS, J.A. \& JANER, J.L. The sedimentation concentration method in Schistosomiasis mansoni. Puerto Rico J. Pub. Health, 9: 283, 1934.

6. PESSOA, S.B., Endemias parasitárias da zona rural brasileira. Fundo Editorial Procienx, São Paulo, 1963. 